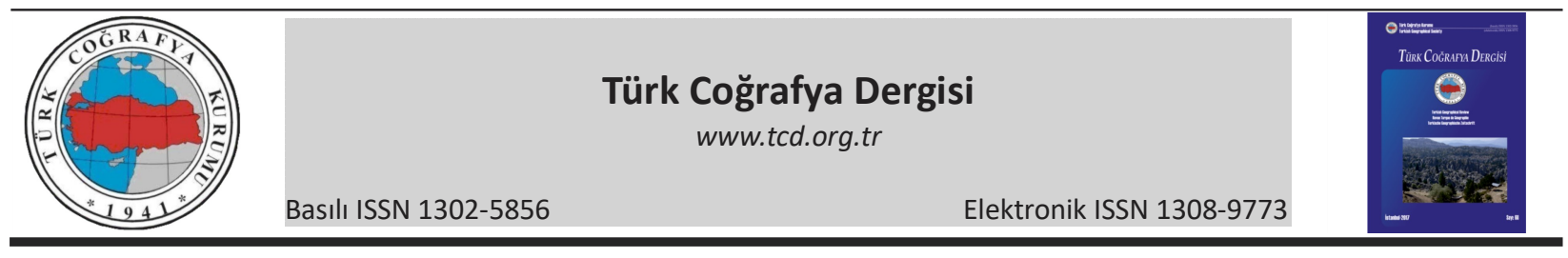

\title{
RASAT verisi kullanarak farklı pan-keskinleştirme yöntemlerinin istatistiksel analizi
}

\section{Statistical analysis of different pan-sharpening methods using RASAT data}

\author{
Saygın Abdikan *a \\ ${ }^{a}$ Bülent Ecevit Üniversitesi, Mühendislik Fakültesi, Geomatik Mühendisliği Bölümü, Zonguldak.
}

\section{MAKALE BILGi}

Geliş/Received: 21.03.2017

Kabul/Accepted: 08.06.2017

Anahtar Kelimeler:

Pan-keskinleştirme

Görüntü birleştirme

RASAT

Kalite analizi

Uzaktan algılama

Keywords:

Pansharpening

Image fusion

RASAT

Quality analysis

Remote sensing

*Sorumlu yazar/Corresponding author

(S. Abdikan) sabdikan@beun.edu.tr

http://dx.doi.org/10.17211/tcd.299099

\begin{abstract}
ÖZ / ABSTRACT
Bu araştrrmada, Türkiye'nin optik uzaktan algılama uydusu olan RASAT uydusuna ait görüntü kullanılarak farklı pan-keskinleştirme teknikleri değerlendirilmiştir. Kullanılan verinin pankromatik bandı (PAN) 7,5 m ve multispektral (MS) bantları (kırmızı, yeşil ve mavi) $15 \mathrm{~m}$ yer örnekleme aralığına sahiptir. Çalışmanın amacı, mekansal olarak iyileştirilmiş ve spektrum bilgisi korunmuş yüksek çözünürlüklü RASAT verilerini elde etmek üzere farklı pan-keskinleştirme yöntemleri kullanarak uydu verisinin performansını araştırmaktır. Bu amaçla Ehlers yöntemi, Yüksek Geçirgenli Filtreleme (High Pass Filtering - HPF), Yoğunluk Renk Doygunluk (Intensity Hue Saturation - IHS) ve Ana Bileşenler Dönüşümü (Principal Component Analysis - PCA) yöntemleri uygulanmış ve karşılaştırılmıştır. Çalışma alanı Türkiye'nin batısında İzmir ili Menemen bölgesinde yer almaktadır. Çalışma alanı ekili alan, çıplak alan, sulak alan, su kütleleri ve mera gibi arazi örtüsü ile kaplıdır. Çalışmada pan-keskinleştirilmiş görüntülerin performansını değerlendirmek için kalitatif ve kantitatif analizler uygulanmıştır. Daha düşük çözünürlüklü çok spektral bantlı veri Pan-keskinleştirilmiş görüntülerle görsel olarak karşılaştırılmış ve renk bozulmaları araştırı mıştır. Kantitatif analiz için farklı istatistiksel metrikler kullanılmıştır. Bu amaçla, Korrelasyon Katsayısı (CC), Evrensel Görüntü Kalitesi İndeksi (UIQI), Karesel Ortalama Hata (RMSE) ve ERGAS metrikleri uygulanmış ve iyileştirilmiş sonuç verilerin kalite değerlendirmeleri karşılaştırılmıştır. Pan-keskinleştirilmiş görüntü sonuçlarına göre Ehlers renk bilgisini en iyi korurken, HPF sonucu istatistiksel açıdan en iyi sonucu sağlamıştır.
\end{abstract}

The research evaluates the image fusion techniques using RASAT image which is one of the optical remote sensing satellites launched by the Republic of Turkey. The data has $7.5 \mathrm{~m}$ ground resolution panchromatic and $15 \mathrm{~m}$ multispectral bands (red, green and blue). The aim of the study is to compare the images fusion methods to achieve spatially improved and spectrally preserved higher resolution RASAT data. The performance of the data was investigated by different image fusion methods. For this purpose, Ehlers fusion, High Pass Filtering (HPF), Intensity Hue Saturation (IHS) and Principal Component Analysis (PCA) data fusion methods were applied and investigated. The study area is located in Menemen Izmir province, west of Turkey. The area has different land use classes such as cultivated fields, bareland, wetland, water body and pasture. Qualitative and quantitative analyses were applied to assess the performance of the fused images. Lower resolution multispectral data was compared to fused images visually and color distortions were investigated. For the quantitative analysis different statistical metrics were utilized. In this frame, Correlation Coefficient (CC), Universal Image Quality Index (UIQI), Root Mean Square Deviation (RMSE) and Relative Dimensionless Global Error in Synthesis-Erreur Relative Globale Adimensionnelle de Synthese (ERGAS) were performed for quality assessments of spatially improved data. Regarding to the results of the pan-sharpening methods it is concluded that Ehlers preserved the best color information while the result of HPF provided higher statistical results.

\section{Giriş}

Uzaktan algılama uyduları farklı spektral ve mekansal özelliklere sahip olmaları bakımından çeşitli uygulamalarda kullanımı mümkün kılmaktadır. Ancak her uydunun yüksek mekansal çözünürlüğe sahip algılayıcısı olmadığı için bazı uygulamalarda kullanımı sınırlı kalmaktadır. Pan-keskinleştirme yaklaşımı aynı yada farklı algıyıcı tarafindan sağlanan iki yada daha fazla görüntü veya spektral bant birleştirerek aynı bölgeye ait daha fazla bilgi üretmek, görüntü yorumlamayı iyileştirmek, sınıflandırma doğruluğunu artırmak, detay bilgisini öne çıkarmak ve zamansal değişim analizini iyileştirmek için kullanılmaktadır (Ghassemian, 2016). Literatürde bu amaç için çeşitli yöntemler geliştirilmiştir (Pohl ve Genderen 2014). Genellikle aynı uyduya ait PAN ve MS görüntüleri birleştirilerek mekansal çözünürlüğü yükseltilmiş MS görüntüler elde edilmiştir (Özendi vd., 2015; 
Teke vd., 2014; Witharana vd. 2013). Bunun dışında literatürde çoklu algılayıcının sağladığı PAN ve MS görüntülerinin (Pohl ve van Genderen, 2014) yanı sıra PAN ve hiperspektal görüntüleri kullanılarak da (Cetin and Musaoglu, 2009; Zoleikani vd., 2016) yapılmış çalışmalar mevcuttur. Bununla birlikte optik görüntüler ile birlikte pankromatik yerine sentetik açıklıklı radar görüntülerinin kullanılmasıyla iyileştirilmiş görüntülerin üretildiği çalışmalar da literatürde yer almaktadır (Lu vd., 2011; Hong vd., 2014; Sanli vd. 2016).

Yapılan pekçok çalışmada çeşitli görüntü birleştirme yöntemleri kullanılmış ve karşılaştırılmıştır (Pohl ve van Genderen, 2014). Pankeskinleştirme yöntemleri ile oluşturulan yeni görüntülerin kalite analizi çalışmalarında genel olarak iki yöntem kullanılmaktadır. Bunlardan ilki görsel analizdir. Bu analizde pan-keskinleştirme sonrasında spektral bilginin korunup korunmadığı incelenir. İkinci yöntem olan istatistiksel analizde çeşitli istatistiksel metrikler kullanılarak orijinal görüntüde meydana gelen değişimler nicel olarak incelenir. Literatürde, sonuçların istatistiksel olarak değerlendirilmesinde pan-keskinleştirilmiş görüntü ile aynı mekansal çözünürlükte bir MS görüntü bulunduğu ve bulunmadığı durumlar için farklı yaklaşımlar ele alınmaktadır (Wald vd., 1997; Özendi vd., 2015).

Özendi vd. (2015), Pleiades-1A görüntüsünün pan-keskinleştirme performansını değerlendirmek için üç yöntem kullanarak görsel ve istatistiksel karşılaştırma yapmıştir. Yöntem olarak PCA, IHS ve brovey yöntemleri incelenmiş, istatistiksel karşılaşturmada CC, RMSE, Göreceli Ortalama Tayfsal Hata (RASE), tayfsal açı haritalayıcı (SAM) ve ERGAS istatistiksel metrikleri ele alınmıştır. Görüntü kalitesi açısından Brovey en iyi sonucu verirken niteliksel olarak IHS yöntemi en iyi sonucu vermiştir. Witharana vd. (2013), GeoEye-1 görüntüsünü kullanarak pan-keskinleştirme yöntemlerini incelemiş ve on iki yöntem değerlendirmiştir. Bunlar sırasıyla, Brovey, renk normalizasyon spektral keskinleştirme, Ehlers, Gram-Schmidt (GS), yüksek geçirgenli filtre (HPF), lokal ortamala eşleme algoritması, lokal ortalama varyans eşleme, modifiye edilmiş yoğunluk renk doygunluk (IHS) yöntemi, ana bileşenler dönüşümü (PCA), eksiltici çözünürlük birleştirme, New Brunswick Üniversitesi görüntü birleştirme algoritması (UNB) ve dalgacık-PCA yöntemidir (WV). Araştırmada farklı spektral ve mekansal metrikler kullanılmış ve Ehlers, WV ve HPF spektral kaliteyi koruyan en iyi yöntemler olarak belirlenmiş. UNB ve GS yöntemleri ise mekansal bilgiyi en iyi koruyan yöntemler olmuştur. Genel olarak en iyi performans gösteren yöntem HPF olarak değerlendirilmiştir. Yüksek çözünürlüklü Worldview-2 uydu görüntüsünün test edildiği çalışmada on yöntem uygulanmış ve farklı istatistiksel yöntemlerle (CC, ERGAS, UIQI, Genişletilmiş kalite indeksi ve Entropi) değerlendirme yapılmıştır (Nikolakopoulos ve Oikonomidis, 2015). Sonuçlara göre Pansharp yöntemi en iyi mekansal iyileştirmeyi sağlarken Ehlers ve HPF spektral bilgiyi en iyi koruyan yöntemler olmuştur.

RASAT ile yapılan çalışmada ise PCA, IHS ve brovey yöntemleri arasında görsel karşılaştırmada PCA en kötü sonucu verirken Brovey en iyi sonucu vermiştir. Kullanılan metrikler arasında ise en iyi sonucu PCA vermiştir (Ozendi vd., 2016). RASAT görüntüleri kullanılarak yapılan diğer bir çalışmada dokuz yöntem uygulanarak metrik karşılaştırmalar değerlendirilmiştir (Teke vd. 2014). Kullanılan yöntemler, PCA, Brovey, GS, IHS, renk doyum değeri (HSV), dalgacık, HPF ve hiperküre renk uzayı yöntemleridir. Kalite analizinde RMSE, SAM, Qave, RASE ve ERGAS yön- temleri ele alınmıştır (Vaiopoulos, 2011). Çalışmada daha çok şehir alanları incelenmiş olup IHS yönteminin tüm metriklerde en başarılı sonuç verdiği görülmektedir. HPF en keskin görüntüyü oluşturmasına rağmen renk bilgisini koruyamadığı belirlenmiştir. En iyi radyometrik doğruluğa sahip pankeskinleştirilmiş görüntüyü sağlayan yöntem olarak HCS yöntemi önerilmiştir.

Yapılmış çalışmalarda görülmektedir ki yöntemler çalışma alanları ve seçilen uydu görüntülerine göre farklı sonuçlar sunmaktadır. Bu çalışmada diğer RASAT çalışmalarından farklı olarak düzlük alanlarda ve daha çok doğal arazi ötrüsünün yer aldığı, yerleşimin yer almadığı bir test alanında farklı pan-keskinleştirme yöntemleri ele alınmış ve RASAT uydusunun performansı farklı arazi örtüsü tipleri için incelenmiştir.

\section{2. Çalışma Alanı ve Metodoloji}

\section{1. Çalışma Alanı}

Çalışma alanı İzmir il sınırında bulunana Memenen ovasında ve Ege Denizine kıyısı olan bölgede yer almaktadır (Şekil 1). Çaış̧ma alanının büyük bir çoğunluğunu farklı doğal alanlar kapsamaktadır bununla birlikte bölgede ekili tarım alanları da yer almaktadır. Bölgenin batısında Ege Denizi yer almaktadır, genel arazi örtüsünü ekili alanlar, çıplak alanlar, sulak alanlar, su kütleleri ve mera alanları oluşturmaktadır. Çalışma alanı Ramsar anlaşmasına göre belirli türlerin korunması ve izlenmesi amacıyla koruma altındadır (Çağırankaya ve Meriç, 2013).
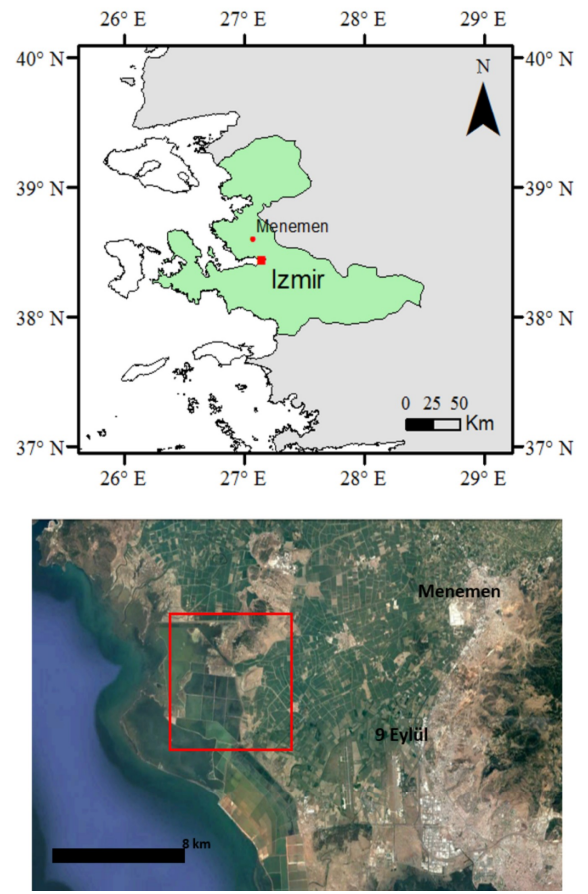

Şekil 1. Çalışma alanı.

Figure 1. Study area.

RASAT uydusu tasarımı ve üretimi Türkiye de gerçekleştirilmiş olan ilk yerli yer gözlem uydusudur. Güneş ile eş zamanlı görüngede bulunan RASAT 7.5 m ve 15 m mekansal çözünürlükte pankromatik ve multispektral görüntü sağlamaktadır. Uyduya ait teknik bilgiler Tablo 1'de sunulmuştur (Erdoğan vd., 2016). 
RASAT kullanıcılara farklı görüntü işleme seviyesinde görüntüler sunmaktadır (Teke vd., 2015). Bu çalışmada seviye 2 (L2) radyometrik ve geometrik düzeltilmiş görüntü kullanılmıştır. Şekil 1'de çalışma alanı ile birlikte uydu görüntüsünün üç bantlı komposit görüntüsü (sırasıyla kırmızı yeşil ve mavi) verilmiştir.

Tablo 1. Uydu görüntüsünün teknik özellikleri.

Table 1. Specification of satellite image.

\begin{tabular}{|l|l|}
\hline Alım tarihi & 02.09 .2012 \\
\hline Algılayıcı & Optic pushbroom \\
\hline Tarama genişliği & $30 \mathrm{~km}$ \\
\hline Mekansal çözünürlük & $7.5 \mathrm{~m}$ Pankromatik \\
& $15 \mathrm{~m}$ Multi-spektral \\
\hline Spektral bantlar $(\mu \mathrm{m})$ & $0.42-0.73$ Pan \\
& $0.42-0.55$ Mavi \\
& $0.55-0.63$ Yeşil \\
& $0.58-0.73$ Kırmızı \\
\hline Radyometrik çözünürlük & 8 bit \\
\hline Zamansal çözünürlük & 4 gün \\
\hline
\end{tabular}

\subsection{Yöntem}

RASAT uydusuna ait aynı tarihte alınmış PAN ve MS görüntülerinin oluşturduğu pan-keskinleştirilmiş görüntülerin kalitesinin incelenmesi dört pan-keskinleştirme yöntemi ele alınmıştır. Bunlar, Ehlers yöntemi, HPF, IHS ve PCA yöntemleridir. Bu yöntemlerden üretilen sonuçların kalitesinin değerlendirilmesi için hem görsel hem de istatistiksel analizler ele alınmış ve orijinal görüntü ile karşılaştırılmıştır.

IHS yönteminde kırmızı, yeşil ve mavi domainde bantları IHS renk uzayına dönüştürülür. Yüksek mekansal çözünürlüğe sahip bir görüntü mekansal çözünürlüğü düşük olan görüntünün yoğunluk (I) bileşeni ile yer değiştirilerek görüntünün mekansal çözünürlüğü iyileştirilir. Sonraki adımda IHS görüntüsüne ters dönüşüm işlemi uygulanır ve yüksek çözünürlüklü RGB MS görüntüsü üretilmiş olur (Pohl ve van Genderen, 1998).

Ehler yöntemi, IHS yöntemi ile birlikte Fourier domain filtre kullanarak spektral bilgiyi korurken mekansal bilgiyi iyileştirmeyi amaçlar. Yöntem, bantların RGB den IHS'ye dönüşümü sonrasında yoğunluk ve yüksek çözünürlüklü görüntü hızlı fourier dönüşümü (Fast Fourier Transportation - FFT) ile frekans domaine dönüştürülür. Daha sonra yoğunluk spektrumuna alçak geçirgenli filtre ve yüksek çözünürlüklü görüntüye ters yüksek geçirgenli filtre uygulanır. Filtrelenmiş bu görüntülere ters FFT uygulanarak yeni, yoğunluk bileşeni iyileştirilmiş bir görüntü oluşturulur. Bu yeni görüntüye ters IHS dönüşümü uygulanarak keskinleştirilmiş RGB görüntüsü elde edilir (Ehlers, 2004).

HPF yöntemi, yüksek çözünürlüklü görüntüye yüksek geçirgenli filte uygulayarak yüksek frekanslı bileşen elde eder. Mekansal bilgiyi içeren yüksek frekans bileşeni düşük mekansal çözünürlüğe sahip MS görüntüsüne eklenerek yeni görüntü elde edilir (Lu vd., 2011).

İstatistiksel bir yöntem olan PCA, verileri birleştirerek yeni korelasyonsuz bir veri seti oluşturur. MS görüntüye PCA uyguladıktan sonra ilk bileşen yüksek çözünürlüklü görüntü ile yer değiştirilir. Ters dönüşüm uygulandıktan sonra mekansal olarak iyileştirilmiş MS görüntüsü elde edilir (Lu vd., 2011).

Pan-keskinleştirme yöntemleri uygulandıktan sonra oluşan görüntülerin kalitesinin izlenmesinde görsel analiz ile birlikte dört farklı nicel analiz de ele alanmıştır. Görsel analizde orijinal MS görüntüsü ile pan-keskinleştirilmiş görüntüler karşılaştırılmış ve renk bilgisinin korunup korunmadığı araştirılmıştr. Nicel analizde dört istatistiksel metrik kullanılarak yine orijinal görüntüye olan benzerlikler incelenmiştir. Bu metrikler CC (Correlation Coefficient), UIQI (Universal Image Quality Index), RMSE (Root Mean Square Deviation) ve ERGAS (Erreur Relative Globale Adimensionnelle de Synthese). CC, original MS ile pankeskinleştirilmiş görüntüler arasındaki korelasyona bakarak spektral benzerliği değerlendirir. Değerler +1 ile -1 arasında değişir ve +1'e yakın değerler yüksek korelasyon gösterir (Witharana vd., 2013). UIQI metriği görüntü distorsiyonunu korelasyon kaybı, parlaklık distorsiyonu ve kontrast distorsiyonunun komposit modeli olarak tanımlanmıştır. Yüksek UIQI değeri yüksek spektral bilgiyi gösterir ve 1'e yakın değer alır (Wang ve Bovik 2002). RMSE metriği her pikseldeki spektral bozulmanın ortalama oranını ifade eder. Sıfır değerine yakın RMSE pankeskinleştirilmiş görüntünün MS görüntüsüne yakın olduğunu gösterir (Witharana vd., 2013). ERGAS, pan-keskinleştirilmiş görüntüdeki spektral distorsiyonu gösterir. Yüksek spektral kaliteli görüntü elde etmek için ERGAS değeri olabildiğince küçük olmalıdır (Alparone vd., 2008).

\section{Bulgular ve Tartışma}

Çıkt görüntülerin kalitesinin kontrolünde hem görsel hem de istatistiksel değerlendirme yapılmıştır. Sonuçlar görsel olarak karşılaştırılırken renk ve keskinlik dikkate alınmıştır. İstatistiksel değerlendirmede yukarıda ifade edilen metrikler incelenmiştir.

\subsection{Görsel Karşılaştırma}

Sonuç ürünlerin görsel karşılaştırılmasında spektral değerlerin ve nesnelerin geometrilerinin korunup korunmadığı kontrol edilmiştir. Sonuçlara göre spektral değerleri en iyi Ehlers yöntemi (Şekil 2c) korumuş onu sırasıyla HPF (Şekil 2f) yöntemi izlemiştir. PCA ve IHS yöntemleri ise kötü sonuçlar vermiştir (Şekil $2 \mathrm{~d}$ ve Şekil 2e). PCA yöntemine ait sonuçlarda spektral distorsiyon özellikle su alanlarında ve bitki örtüsünün bulunduğu bölgelerde daha belirgindir, her iki bölgede de daha canlı renk tonları görülmektedir. IHS yönteminde ise PCA'nın tersine daha soluk renk tonları göze çarpmaktadır. Pankeskinleştirme sonrası görüntü üzerindeki lineer detaylar Şekil 3'de gösterilmiş̧tir. Keskinlik dikkate alındığında özellikle yüzey şekline ait lineer detaylarda HPF yöntemi daha belirgin sonuçlar sunmaktadır (Şekil 3f). Diğer yöntemler ise HPF'ye göre bulanık sonuçlar vermiştir.

\section{2. İstatistiksel Karşılaştırma}

Görsel karşılaştırmadan sonra kullanılan yöntemlere ait sonuçlar üzerinden nicel değerlendirilmeler yapılmıştır. Her üç bant ayrı ayrı ele alınmış ayrıca üç bantın ortalaması alınarak görüntüye ait genel sonuçlar da Şekil 4.'de gösterilmiştir. Ehlers yöntemi tüm bantlarında CC metrik sonuçlarında en iyi sonucu vermiştir, Ehlers yöntemi sırasıyla PCA, IHS ve HPF yöntemleri izlemektedir (Şekil 4a). UIQI değerleri karşılaştırıldığında HPF ve Ehlers yöntemlerine ait sonuçlar birbirine çok yakındır, B1 ve $\mathrm{B} 2$ de Ehler çok az farkla birinci olurken B3 ve ortalama de- 

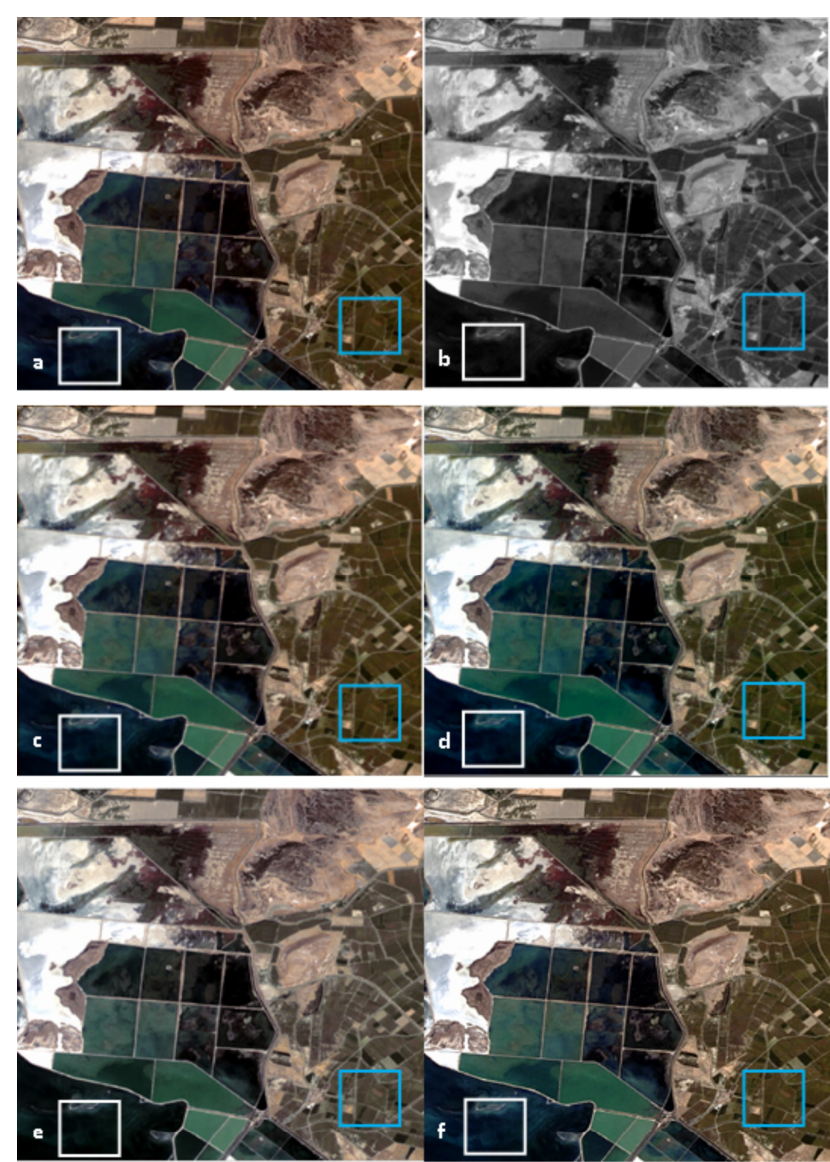

Şekil 2. Görsel karşılaştırma; a- MS RASAT, b- PAN RASAT, c-Ehlers, d-PCA, e-IHS, f-HPF (Beyaz ile seçilmiş bölge su alanını, mavi ile seçilmiş bölge bitki örtüsünün bulunduğu alanı göstermektedir.)

Figure 2. Visual comparison; a-MS RASAT, b-PAN RASAT, $c-E h l e r s, d-P C A, e-I H S, f-H P F$ (Selected white region shows the water area and blue region shows the vegetated area).

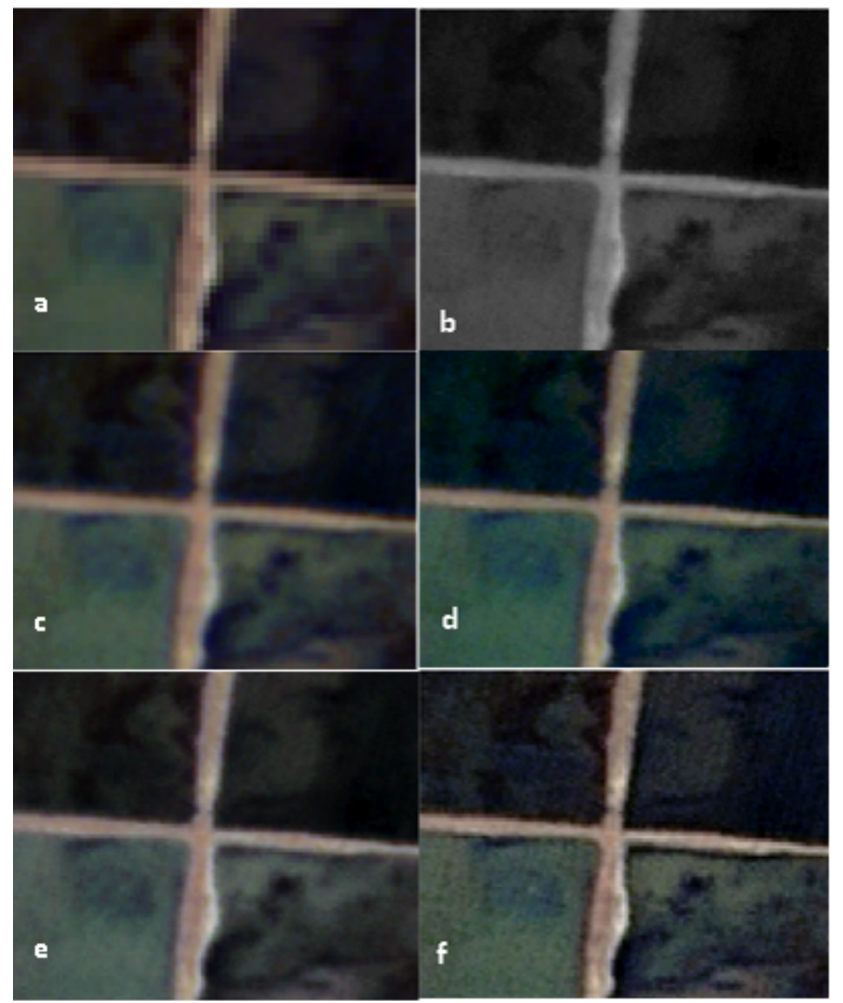

Şekil 3. Lineer detayların karşılaştırmasi; a- MS RASAT, b- PAN RASAT, c-Ehlers, d-PCA, e-IHS, f-HPF. Figure 3. Comparison of linear details; $a-M S$ RASAT, b-PAN RASAT, c-Ehlers, d-PCA, e-IHS, f-HPF. 
ğerlerde HPF yine çok az farkla öne geçmektedir (Şekil 4b). PCA yöntemine ait sonuç ortalama bant için 0,6 olup en kötü sonucu vermektedir. ERGAS indeksine ait sonuçlarda HPF yöntemi minimum değerler ile en iyi değerleri sağlamaktadır (Şekil 4c). Bu değeri sırasıyla Ehlers, IHS ve PCA yöntemleri izlemektedir. Burada da PCA maksimum ERGAS değerleri ile en kötü sonucu sunmaktadır.

RMSE sonuçlarında da ERGAS sonuçlarına benzer sonuçlar yer almaktadır. HPF yöntemine ait sonuçlar minimum iken PCA yönremine ait sonuçlar maksimum RMSE değerleri vermektedir (Şekil 4d). İkinci en iyi yöntem ise Ehlers yöntemidir. Ehlers ve HPF spektral bilgiyi en iyi koruyan yöntemler olmaları açısından benzerlik gösteren Nikolakopoulos ve Oikonomidis (2015) ve Witharana vd. (2013) çalışmalarını destekler niteliktedir. Ancak RASAT uydu görüntülerinin değerlendirildiği diğer çalışmada metriklerde en iyi sonucu IHS yöntemi vermesine rağmen bu çalışmada HPF en iyi sonuçları vermiştir (Teke vd. 2014).

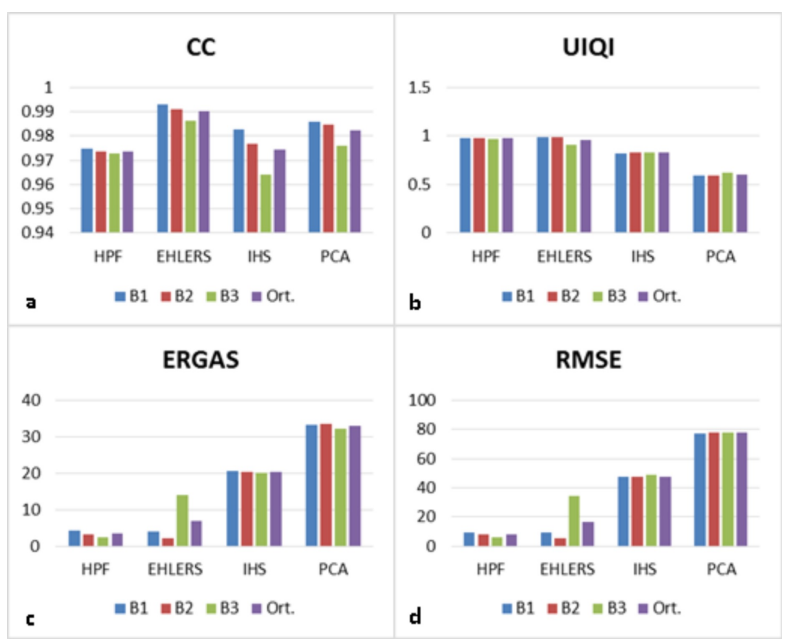

Şekil 4. Nicel değerlendirme sonuçları; a-CC (ideal değer:1), b-UIQI (idea değer:1), c-ERGAS (ideal değer:0), d-RMSE (ideal değer:0).

Figure 4. Results of quantitative assessment; a-CC (ideal value:1), b-UIQI (ideal value:1), c-ERGAS (ideal value:0), d-RMSE (ideal value:0).

\section{Sonuç}

Amacı her zaman geometrik doğruluğu maksimum spektral kaybın minimum olduğu yeni görüntüler üretmek olan pankeskinleştirme işlemlerine olan ilgi son zamanlarda hız kazanmış ve bu konuda gelişen teknoloji ve uydu sistemleri ile birlikte yeni algoritmalar öne sürülmüştür. Pan-keskinleştirme yöntemleri kullanarak doğal alanların dominant olduğu bir bölgeye ait RASAT uydu görüntüsünün performansının değerlendirildiği bu çalışmada seçilen dört yöntem ile mekansal çözünürlüğün artrrıldığı ancak her yöntemin spektral bilgiyi koruyamadığı belirlenmiştir. Görsel ve istatistiksel olarak değerlendirilen Ehlers, HPF, IHS ve PCA yöntemlerinden HPF yönteme ait nicel değerlendirmelerin en iyi sonucu verdiği, alternatif olarak da Ehlers yöntemin ikinci yöntem olarak ele alınabileceği sonucu çıkartılmıştır. İstatistiksel karşılaştırma amaçlı kullanılan CC, UIQI, RMSE ve ERGAS sonuçlarına göre PCA sadece CC metriğine göre ikinci sırayı almıştır. Diğer metriklerde ise en kötü sonucu vermiştir. Bu nedenle sadece bir metrik yerine çoklu metrik değerlerin karşılaştırılmasının daha uygun olacağı sonucu çıkar- tılmıştır. Ayrıca pan keskinleştirilmiş görüntü ile aynı mekansal çözünürlükte bir MS görüntü bulunmadığı durumda kullanılan Wald (1997) protokolü ile diğer metrikler de ele alınabilir (Jagalingam ve Hegde, 2015). Sonuç olarak pan-keskinleştirme yöntemleri arasında en kötü sonucu PCA yöntemin verdiği tespit edilmiştir.

Pan-keskinleştirilmiş görüntüler, mekansal çözünürlüğü artırarak daha doğru tematik harita üretmek üzere yapılan sınıflandırmaların doğruluğu arttırmak ile birlikte yer yüzü şekillerine ait detayların da daha doğru ortaya çıkmasına katkı sağlayacaktor (Lu vd., 2011; Sanlı vd., 2016). Daha detaylı bir araştırma için sonraki çalışmalarda RASAT görüntüleri kullanılarak farklı alanların farklı pan-keskinleştirme yöntemleri ile değerlendirilmesi ve değerlendirme sonuçlarının sınıflandırma sonuçlarına olan katkısının araştırılması planlanmıştır.

\section{Kaynakça}

Alparone, L., Aiazzi, B., Baronti, S., Garzelli, A., Nencini, F. ve Selva, M. (2008). "Multispectral and Panchromatic Data Fusion Assessment without Reference", Photogrammetric Enginnering and Remote Sensing 74:193-200.

Cetin, M. ve Musaoglu, N. (2009). "Merging hyperspectral and panchromatic image data: qualitative and quantitative analysis", International Journal of Remote Sensing, 30:1779-1804.

Çağırankaya, S. S. ve Meric, B. T. (2013). "Turkey's important wetlands: RAMSAR Sites", Ankara, Turkey: Ministry of Forestry and Water Affairs, General Directorate of Nature Conservation and National Parks.

Erdoğan M., Yılmaz A., Eker O., 2016. "The georeferencing of RASAT satellite imagery and some practical approaches to increase the georeferencing accuracy", Geocarto International, 31:6, 647-660.

Ehlers, M. 2004. "Spectral Characteristics Preserving Image Fusion Based on Fourier Domain Filtering." In Proceedings of SPIE, Conference on Remote Sensing for Environmental Monitoring, GIS Applications, and Geology, IV. Remote Sensing Europe 2004, Maspalomas, Gran Canaria, Spain, 5574: 1-13.

Ghassemian H., 2016. "A review of remote sensing image fusion methods", Information Fusion 32 (2016) 75-89.

Hong, G., Zhang, A., Zhou, F. ve Brisco, B. (2014). "Integration of optical and synthetic aperture radar (SAR) images to differentiate grassland and alfalfa in Prairie area", International Journal of Applied Earth Observation and Geoinformation 28:12-19.

Jagalingam, P. ve Hegde A.V. (2015). "A Review of Quality Metrics for Fused Image", Aquatic Procedia, 4: 133- 142.

Lu, D., Li, G., Moran, E., Dutra, L. ve Batistella, M. (2011). "A comparison of multisensor integration methods for land cover classification in the Brazilian Amazon", GIScience \& Remote Sensing 48: 345-370.

Nikolakopoulos K. ve Oikonomidis D. (2015). "Quality assessment of ten fusion techniques applied on Worldview-2", European Journal of Remote Sensing, 48: 141-167.

Ozendi, M., Topan, H., Oruc, M. ve Cam, A. (2015). "Pan-sharpening quality investigation of PLÉlADES-1A images", Geocarto International, DOI: 10.1080/10106049.2015.1094520.

Ozendi, M., Topan, H., Cam, A. ve Bayık, Ç. (2016). "Pan Sharpening Quality Investigation Of Turkish In-Operation Remote Sensing Satellites: Applications with RASAT And GÖKTÜRK-2 Images", Int. Arch. Photogramm. Remote Sens. Spatial Inf. Sci., XLII-2/W1, 131135, Prag.

Pohl, C., ve Van Genderen J., (1998). "Review Article Multisensor Image Fusion in Remote Sensing: Concepts, Methods and Applications." International Journal of Remote Sensing 19: 823-854.

Pohl C. ve van Genderen J. (2014). "Remote sensing image fusion: an update in the context of Digital Earth", International Journal of Digital Earth, 7: 158-172. 
Sanli, F.B., Abdikan, S., Esetlili, M.T. ve Sunar F. (2016). "Evaluation of image fusion methods using PALSAR, RADARSAT- 1 and SPOT images for land use/ land cover classification", Journal of the Indian Society of Remote Sensing, doi:10.1007/s12524-016-0625-y

Teke, M., Seyfioğlu, M.S., Ağçal, A. ve Gürbüz, Z. (2014). "RASAT Uydu Görüntülerinin Optimal Pankeskinleştirilmesi", IEEE 22nd Signal Processing and Communications Applications Conference (SIU 2014), 1967-1970, Trabzon.

Teke, M., Tevrizoğlu, İ., Öztoprak, A.F., Demirkesen, C., Açıkgöz, i.S., Gürbüz, S.Z., Küpcü R. ve Avenoğlu B. (2015). "GEOPORTAL: TÜBiTAK UZAY Satellite Data Processing and Sharing System", 7th International Conference on Recent Advances in Space Technologies (RAST), İstanbul.

Vaiopoulos, A. D. (2011). "Developing Matlab scripts for image analysis and quality assessment", Proceedings of SPIE Earth Resources and Environmental Remote Sensing/GIS Applications II 8181, 81810B, Prag.

Wald, L., Ranchin, T. ve Mangolini, M. (1997). "Fusion of satellite images of different spatial resolutions: Assessing the quality of resulting images", Photogrammetric Engineering and Remote Sensing, 63(6): 691-699,

Wang, Z. ve Bovik, A. C. (2002). "A universal image quality index." Signal Processing Letters, IEEE, 9: 81-84.

Witharana, C, Civco, D.L. ve Meyer, TH. (2013). "Evaluation of pansharpening algorithms in support of earth observation based rapidmapping workflows", Applied Geography 37: 63-87.

Zoleikani, R., Zoej, M.J.V. ve Mokhtarzadeh, M. (2017). “Comparison of Pixel and Object Oriented Based Classification of Hyperspectral Pansharpened Images", Journal of the Indian Society of Remote Sensing 45: 25-33. 